\title{
PENGUKURAN KECEPATAN GELOMBANG SEISMIK MENGGUNAKAN METODE REFRAKSI PADA LAPISAN TANAH DANGKAL
}

\author{
Admiral Musa Julius ${ }^{*}$, Rian Mahendra Taruna², Shandy Yogaswara Surya Putra ${ }^{3}$, Pande Komang Gede Arta \\ Negara ${ }^{4}$, Bryan Fitzgerald Amos Rumy ${ }^{5}$, Alghani Yullatifah6, Else Nopianti ${ }^{7}$, Nurain Silvana Akuba ${ }^{8}$, Taufan \\ Taufik $^{9}$, Hendri Subakti ${ }^{10}$, dan I Dewa Ketut Kerta Widana ${ }^{11}$

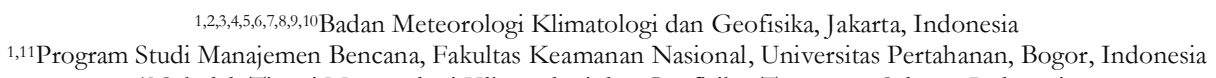

\begin{abstract}
Abstrak Gempabumi kuat dan dirasakan dengan kekuatan magnitudo 6.5 terjadi di $119 \mathrm{~km}$ ke arah tenggara Kabupaten Cilacap, Propinsi Jawa Tengah pada kedalaman $48 \mathrm{~km}$. Gempabumi tersebut berpusat di laut pada koordinat $8.48^{\circ}$ LS dan 109.17 BT pada tanggal 25 Januari 2014. Gempabumi tersebut memicu dampak kerusakan di beberapa lokasi, termasuk kabupaten Banyumas, Kebumen, Cilacap dan Purworejo. Dalam rangka mitigasi bahaya alam kebumian, maka penelitian ini bertujuan untuk mengetahui hubungan antara kecepatan gelombang seismik dengan kedalaman lapisan-lapisan dekat permukaan pada struktur geologi dangkal. Metode yang digunakan dalam penelitian ini adalah metode seismik refraksi. Metode ini dilakukan dengan menginterpretasi sinyal seismik dari gelombang buatan manusia yang menjalar di dekat permukaan bumi. Seismogram akan menampilkan waktu tempuh gelombang, jarak antar gelombang dan sumber gelombangnya sendiri. Struktur lapisan geologi yang ada di dalam bumi dapat diperkirakan berdasarkan besarnya kecepatan gelombang seismik. Penelitian ini berlokasi di area kampus Lembaga Ilmu Pengetahuan Indonesia (LIPI) Karangsambung. Pengukuran dilakukan mengingat lokasinya yang dekat dengan pusat gempabumi dan keunikan batuannya yang terbentuk dari pengangkatan lantai dasar samudra. Berdasarkah hasil penelitian diketahui bahwa terdapat hubungan antara kecepatan gelombang seismik dengan kedalaman lapisan-lapisan dekat permukaan. Semakin dalam lapisan tanah dari permukaan bumi, maka kecepatan gelombang seismik akan semakin tinggi.
\end{abstract}

Kata kunci: seismik refraksi, bahaya kebumian, sifat tanah

\begin{abstract}
The strong and felt earthquake with magnitude 6.5 occurred in $119 \mathrm{~km}$ to the southeast of Cilacap Regency, Central Java Province at a depth of $48 \mathrm{~km}$. The earthquake centered on the sea at coordinates 8.480 latitude and 109.170 east longitude on January 25, 2014. The earthquake triggered damage in several locations, including the districts of Banyumas, Kebumen, Cilacap and Purworejo. In order to mitigate natural hazards, this study aims to determine the relationship between seismic wave velocity and depth of layers near the surface in shallow geological structures. The method used in this study is the seismic refraction method. This method is done by interpreting seismic signals from man-made waves that spread near the surface of the earth. The seismogram will display the travel time of the waves, the distance between the waves and the source of the waves themselves. The structure of the geological layers that exist in the earth can be estimated based on the magnitude of the seismic wave velocity. This research is located in the campus area of the Indonesian Institute of Sciences Karangsambung. Measurements were made considering its location close to the center of the earthquake and the uniqueness of the rock formed by the removal of the ocean floor. Based on the results of the study it is known that there is a relationship between seismic wave velocity and the depth of the layers near the surface. The deeper the layer of soil from the earth's surface, the seismic wave velocity will be higher.
\end{abstract}

Keywords: seismic refraction, geo-hazard, soil properties

\section{PENDAHULUAN}

Pada tanggal 25 Januari 2014 lalu Kebumen dikejutkan oleh kejadian gempabumi merusak yang terjadi di laut selatan Kebumen, Jawa Tengah. Gempabumi tersebut berkekuatan magnitudo 6.5 yang berlokasi di laut pada jarak $119 \mathrm{~km}$ ke arah tenggara Kabupaten Cilacap, Propinsi Jawa Tengah pada kedalaman $48 \mathrm{~km}$. Informasi ini tidak diikuti peringatan dini tsunami. Gempabumi ini dirasakan skala 
guncangan III - IV MMI di Cilacap, Yogyakarta, Purbalingga, Tasikmalaya, Bantul, Pangandaran, Klaten, Magelang, Solo, Demak, Garut, Purwokerto, dan Pemalang; Skala guncangan II - III MMI di Cirebon; dan skala guncangan II MMI di Jakarta. Catatan menyebutkan terdapat empat kabupaten terdampak gempabumi, yakni kabupaten Banyumas, Cilacap, Kebumen, dan Purworejo (Pusat Gempabumi dan Tsunami BMKG, 2019).

Kerusakan di kabupaten Banyumas berada di Kecamatan Pekuncen, ditemukan 125 rumah rusak yang tersebar di Desa Tumiyang, Kranggan, Pasiraman, Karangklasem, Cikembulan, dan Candinegara, sedangkan di Kecamatan Karanglewas ditemukan kerusakan rumah sebanyak 16 unit yang tersebar di Desa Sinyalangu 15 unit dan Desa Babakan 1 unit. Kemudian di Kecamatan Kedungbanteng Desa Melung ditemukan rumah rusak sebanyak 3 unit, dan di Kecamatan Kemranjen Desa Nusamangir ditemukan rumah rusak sebanyak 3 unit. Kerusakan lainnya di kabupaten Cilacap ditemukan 21 unit rumah rusak, di kabupaten Kebumen 3 unit rumah rusak parah, dan di kabupaten Purworejo ditemukan 9 rumah rusak (Pusat Gempabumi dan Tsunami BMKG, 2019).

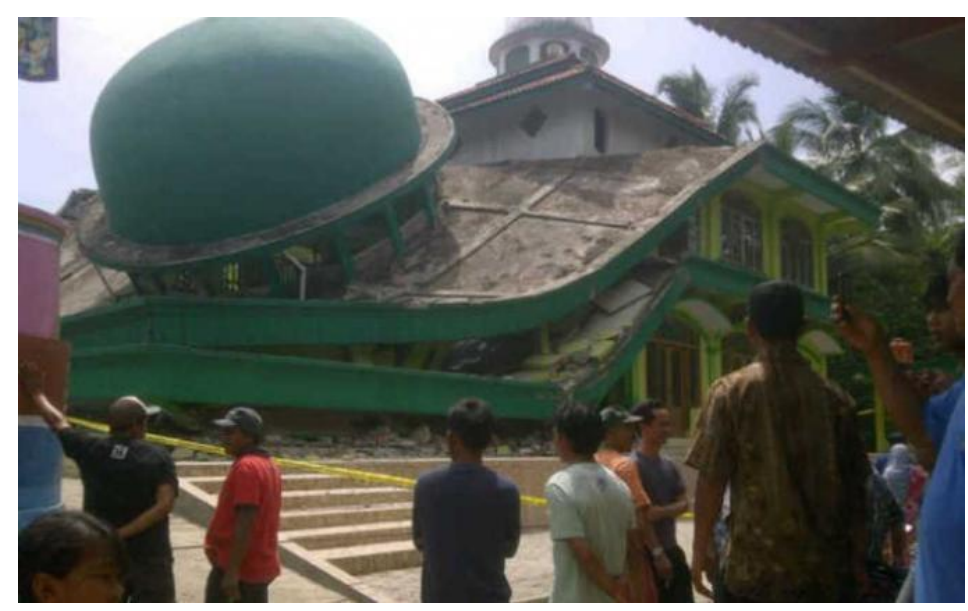

Gambar 1. Gambaran kerusakan akibat gempa di Banyumas pada 25 Januari 2014 (Sumber: Tribun Jogja, 2014)

Berdasarkan permasalahan tersebut maka peneliti merasa perlu untuk mengetahui seperti apa gambaran struktur lapisan bawah permukaan area pengukuran. Kegiatan pengukuran dilakukan di Karangsambung Kebumen yang bertujuan untuk mendapatkan data berupa ketebalan lapisan dari lapisan paling atas sampai paling bawah, yang bisa dicapai oleh energi gelombang seismik yang dihasilkan oleh sumber buatan, khususnya di area pengukuran. Pengukuran ini juga bertujuan menggambarkan kondisi struktur lapisan bawah permukaan area pengukuran (Sagala et al., 2017). Pengukuran ini akan bermanfaat untuk mengetahui ketebalan dari lapisan bawah permukaan bumi di area kampus LIPI karena keunikan batuannya yang berasal dari lantai dasar samudra. Pengukuran ini menggunakan metode seismik refraksi, yang kemudian dilakukan interpretasi litologi unsur penyusun dari lapisan tersebut. Pengukuran ini diharapkan mampu menjawab pertanyaan perbedaan kuantitas dampak di atas.

Geofisika memiliki berbagai metode yang dapat digunakan untuk melakukan berbagai kajian kebumian, diantaranya metode seismik, metode gravitasi, metode magnet bumi, dan metode geolistrik. Metode seismik merupakan salah satu metode yang sering digunakan dalam teknik geofisika disebabkan metode seismik memiliki resolusi akurat dalam menentukan dan memodelkan struktur geologi bawah permukaan bumi yang heterogen. Metode seismik dibagi dua yakni metode seismik refleksi (pantul) dan seismik refraksi (bias). Dalam seismik refleksi, dasar metodanya adalah perambatan gelombang bunyi darisumber getar ke dalam bumi atau formasi batuan, kemudian gelombang tersebut dipantulkan ke permukaan oleh bidang pantul yang merupakan bidang batas suatu lapisan yang mempunyai kontras akustik impedansi. Di permukaan bumi gelombangitu ditangkap oleh serangkaian instrument penerima (geophone/hydrophone) yang disusun membentuk garis lurus terhadap sumber ledakan atau profil line. Seismik refraksi biasanya digunakan untuk menentukan struktur geologi dangkal sedangkan metode seismik refleksi biasa digunakan untuk menentukan struktur geologi dalam (Agus et al., 2018). Seismik 
refraksi dihitung berdasarkan waktu yang dibutuhkan oleh gelombang untuk menjalar pada batuan dari posisi sumber seismik menuju penerima pada berbagai jarak tertentu. Pada metode ini, gelombang yang terjadi setelah sinyal pertama (firstbreak) diabaikan, karena gelombang seismik refraksi merambat paling cepat dibandingkan dengan gelombang lainnya kecuali pada jarak (offset) yang relatif dekat sehingga yang dibutuhkan adalah waktu pertama kali gelombang diterima oleh setiap geophone (Nurdiyanto et al, 2011).

Material penyusun interior bumi bersifat elastis, sehingga apabila suatu gelombang dibangkitkan di permukaan bumi maka gelombang seismik akan menjalar ke segala arah (berbentuk spheris). Karena interior bumi bersifat heterogen, maka bumi bagian dalam terdiri dari lapisan-lapisan. Pada bidang batas antara lapisan, gelombang seismik sebagian akan dipantulkan (refleksi) dan sebagian lagi akan diteruskan (dibiaskan) ke permukaan bumi (Gambar 2). Di permukaan bumi, gelombang tersebut akan diterima oleh beberapa sensor detektor penerima gelombang (geofon) yang akan diteruskan ke alat akuisisi data. Alat akuisisi data akan mendapat informasi berupa waktu tempuh gelombang seismik, jarak antara gelombang seismik, dan sumber gelombang seismik. Struktur lapisan geologi yang ada di dalam bumi dapat diperkirakan berdasarkan besarnya kecepatan (BNPB, 2016).

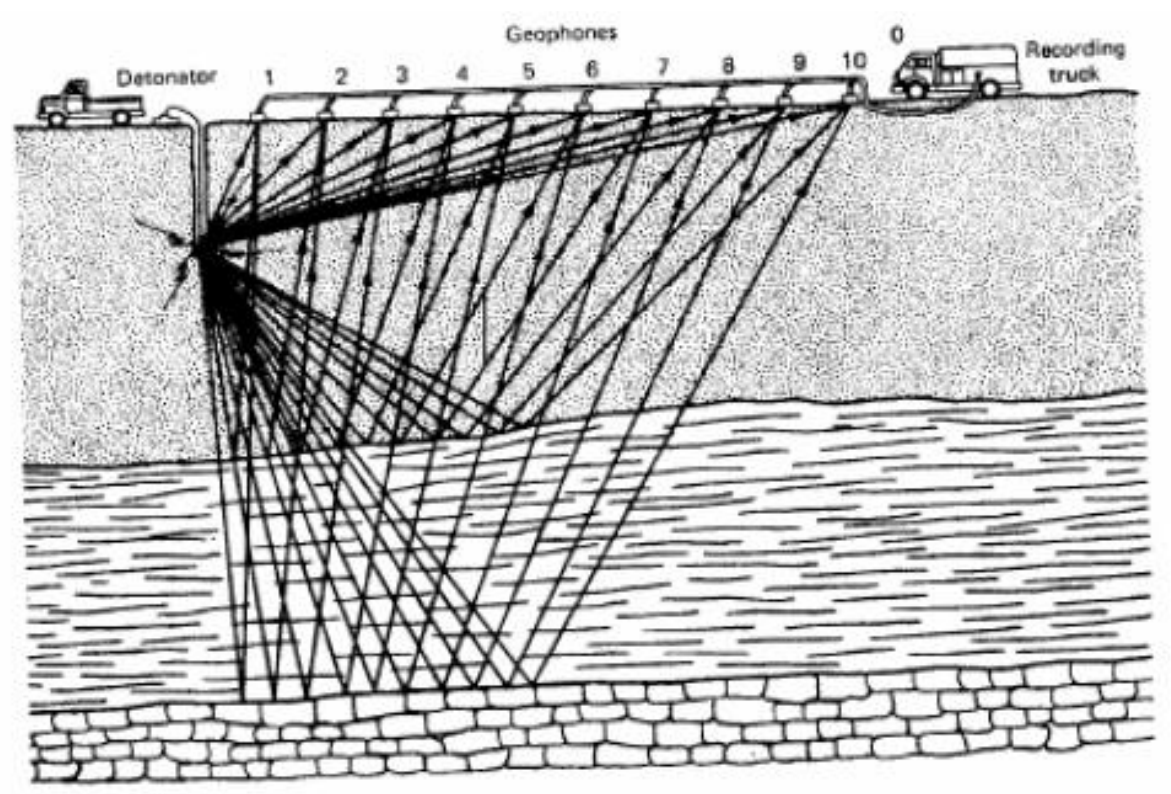

Gambar 2. Penjalaran gelombang seismik di bawah permukaan bumi

(Sumber: Tjetjep, 1995)

\section{METODE PENELITIAN}

Berbagai asumsi yang dipakai untuk medium bawah permukaan bumi antara lain menurut Sismanto (1999) yaitu: 1) Medium bumi dianggap berlapis-lapis dan tiap lapisan menjalarkan gelombang seismik dengan kecepatan yang berbeda; dan 2) Semakin bertambah kedalaman batuan, lapisan bumi makin kompak. Sedangkan anggapan yang dipakai untuk penjalaran gelombang seismik adalah: 1) Panjang gelombang seismik lebih kecil dari ketebalan lapisan bumi. Hal ini memungkinkan setiap lapisan bumi akan terdeteksi; 2) Gelombang seismik dipandang sebagai sinar seismik yang memenuhi hukum Snellius dan prinsip Huygens; 3) Pada bidang batas antar lapisan, gelombang seismik menjalar dengan kecepatan gelombang pada lapisan dibawahnya; dan 4) Kecepatan gelombang bertambah dengan bertambahnya kedalaman.

Prinsip utama metode refraksi adalah penerapan waktu tiba gelombang pertama, baik langsung maupun gelombang refraksi. Mengingat gelombang $\mathrm{P}$ lebih cepat daripada gelombang $\mathrm{S}$ maka kita hanya memperhatikan gelombang P. Hubungan ini dipakai untuk menjelaskan metode pembiasan dengan sudut datang kritis seperti yang ditunjukkan pada gambar 3 sebagai berikut. 


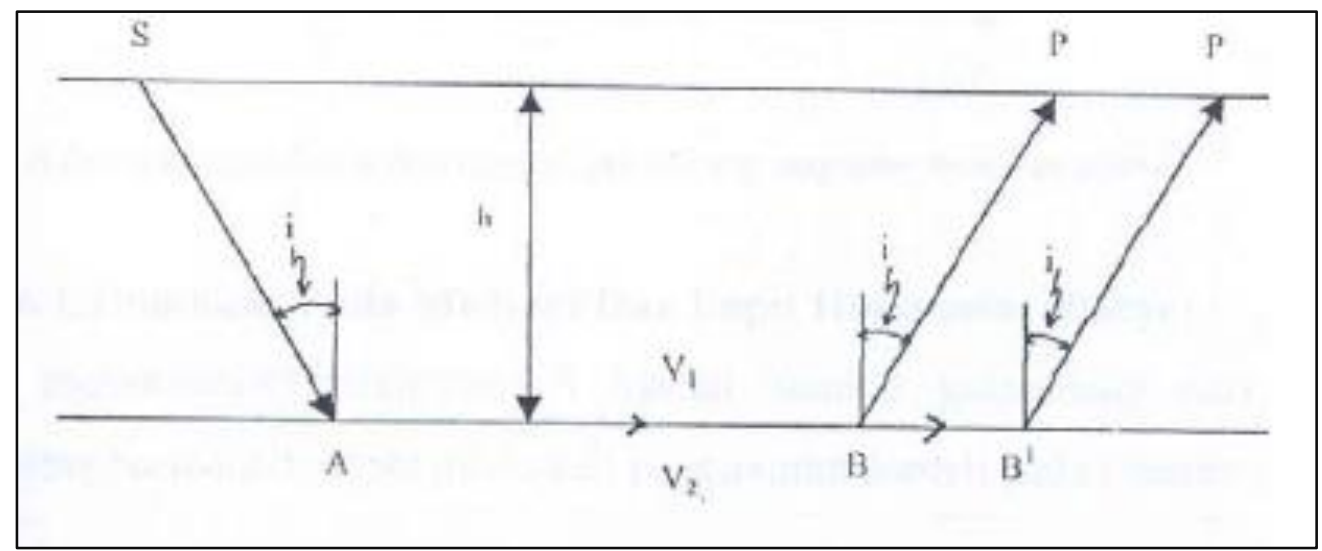

Gambar 3. Pembiasan dengan sudut datang kritis (Sumber: Tjetjep, 1995)

Gambar 3 memperlihatkan gelombang dari sumber $\mathrm{S}$ menjalar pada medium $\mathrm{V}_{1}$, dibiaskan kritis pada titik A sehingga menjalar pada bidang batas lapisan. Dengan memakai prinsip Huygens pada bidang batas lapisan, gelombang ini dibiaskan ke atas setiap titik pada bidang batas itu hingga sampai ke detektor P di permukaan. Jadi gelombang yang dibiaskan di bidang batas yang datang pertama kali di titik P pada bidang batas diatasnya adalah gelombang yang dibiaskan dengan sudut datang kritis (Raharjo, 2002).

Secara umum metode interpretasi seismik refraksi dapat dikelompokkan menjadi tiga kelompok utama, yaitu intercept time, delay time method dan wave front method (Taib, 1985). Metode interpretasi yang paling mendasar dalam analisis refraksi data seismik adalah intercept time (Tjetjep, 1995). Kedalaman lapisan di bawah geophone dapat ditentukan dengan dua cara yaitu berdasarkan waktu penggal (intercept time) $\mathrm{T}_{\mathrm{i}}$ dan jarak kritis $\mathrm{X}_{\mathrm{o}}$. Untuk menentukan kedalaman di bawah sumber gelombang medium dua lapis miring dengan kemiringan $\xi$, perlu diadakan pengukuran bolak-balik yaitu, pengukuran kearah perlapisan naik $\left(U_{p-D i p}\right)$ dan pengukuran ke arah perlapisan turun (Down-Dip) yang ditunjukkan pada gambar 4 dan gambar 5 .

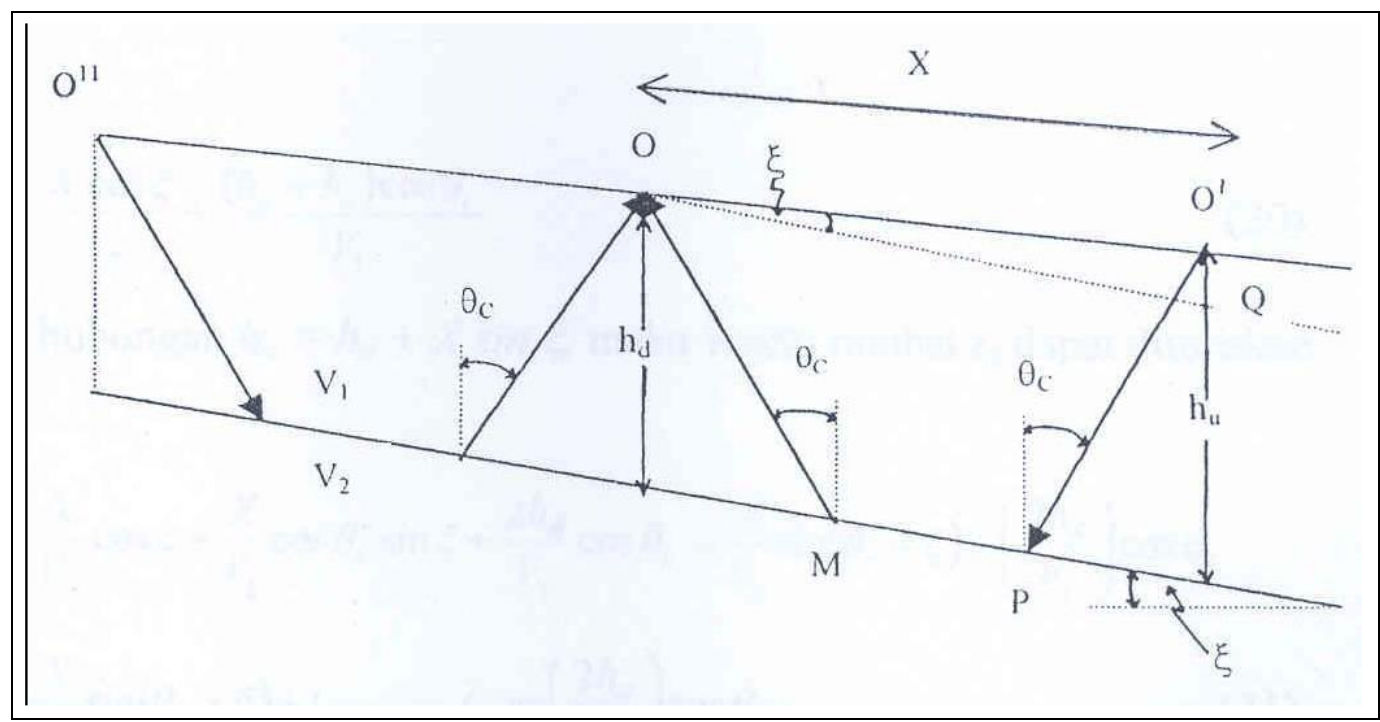

Gambar 4. Penjalaran gelombang seismik untuk dua lapis miring (Sumber: Tjetjep, 1995) 


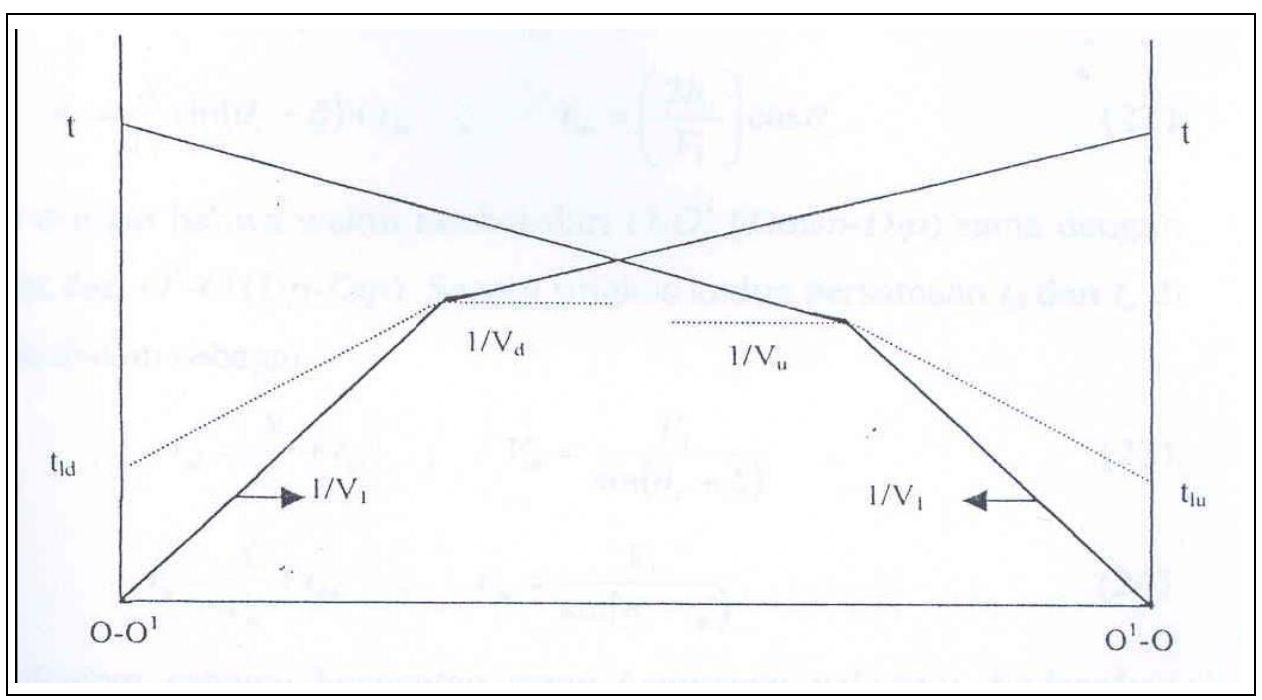

Gambar 5. Grafik hubungan jarak - vs- waktu pada pengukuran up-dip dan down-dip (Sumber: Tjetjep, 1995)

Untuk menentukan kedalaman atau ketebalan suatu lapisan tidak hanya terbatas pada lapisan di bawah sumber gelombang saja. Penentuan kedalaman lapisan di bawah geofon dapat dilakukan dengan metode waktu tunda (Delay Time) (Gambar 6 dan Gambar 7):

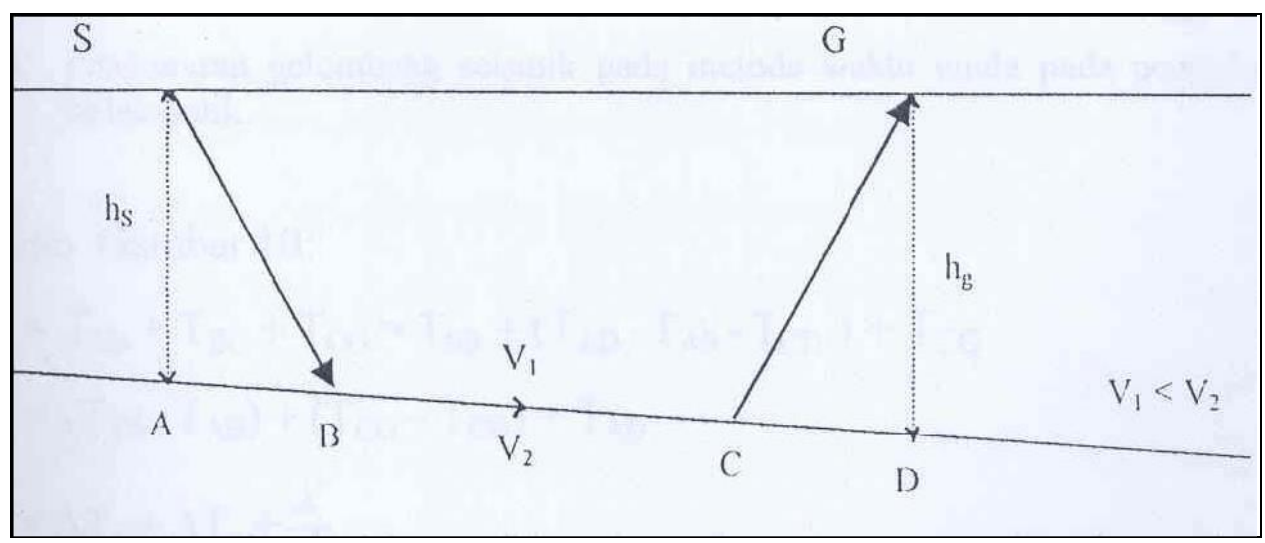

Gambar 6. Pengukuran kedalaman di bawah geofon dengan metode waktu tunda (Sumber: Tjetjep, 1995)

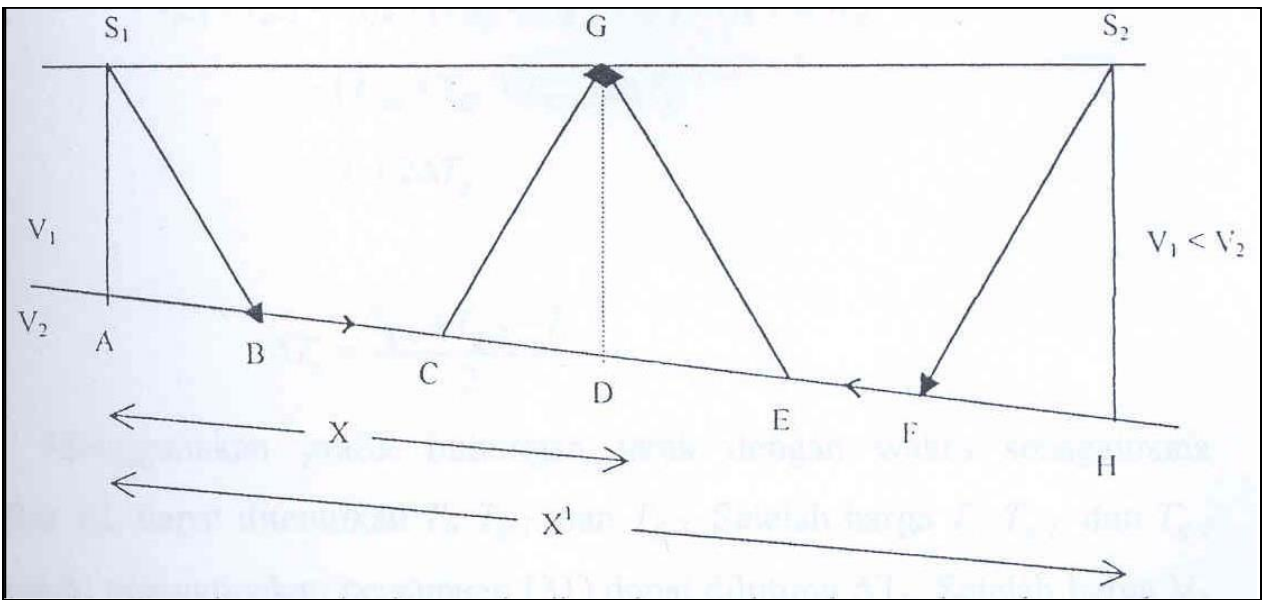

Gambar 7. Pengukuran gelombang seismik pada metode waktu tunda pada pengukuran bolak-balik (Sumber: Tjetjep, 1995) 
Pengukuran dilakukan pada tanggal 10-13 Juli 2015 di area Kampus LIPI. Daerah survei pengukuran ditampilkan pada gambar 8 sebagai berikut:

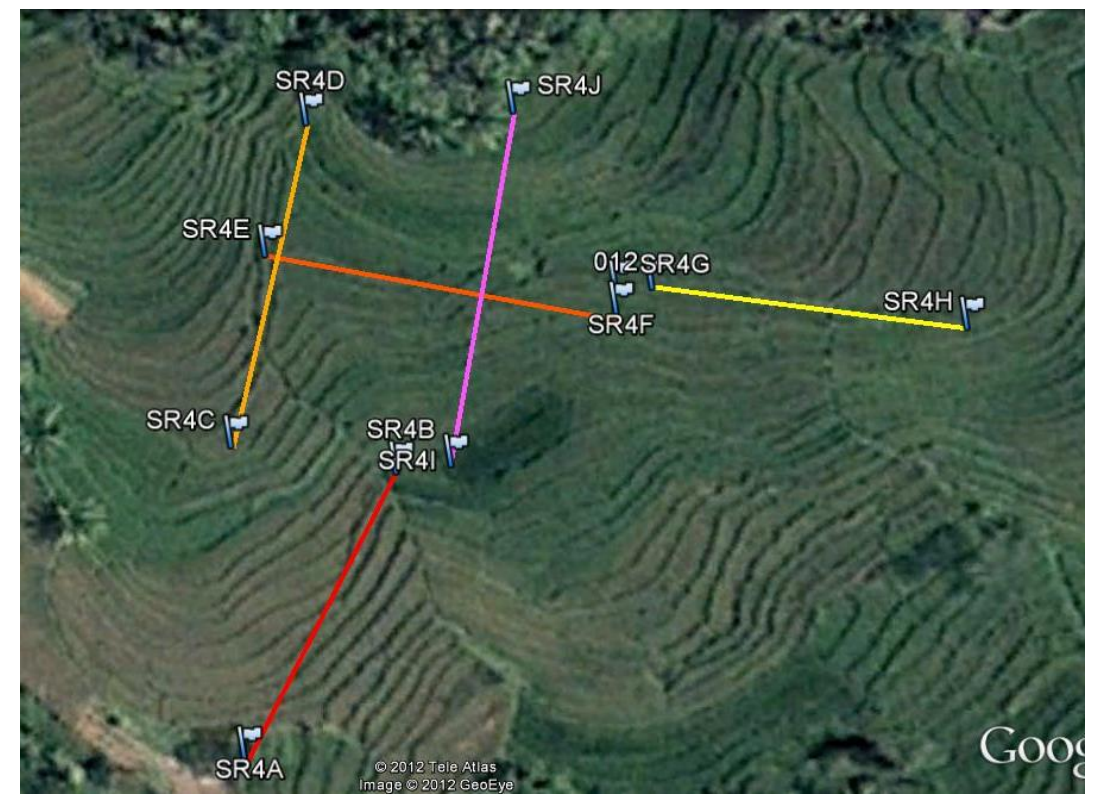

Gambar 8. Peta area pengukuran seismik refraksi (Sumber: Google Earth, 2015)

Peralatan yang digunakan berupa beberapa alat yaitu unit utama refraksi, aki, geofon, palu seberat $5 \mathrm{~kg}$, piringan tembak (shoot plate), meteran gulung $(100 \mathrm{~m})$, kabel geofon, inverter, sensor pemicu (trigger), buku panduan, catu daya (charger), media penyimpanan (flashdisk), alat tulis, kabel USB to serial, kabel serial, GPS, kompas, dan laptop. Rangkaian peralatan tersebut digambarkan pada Gambar 9.

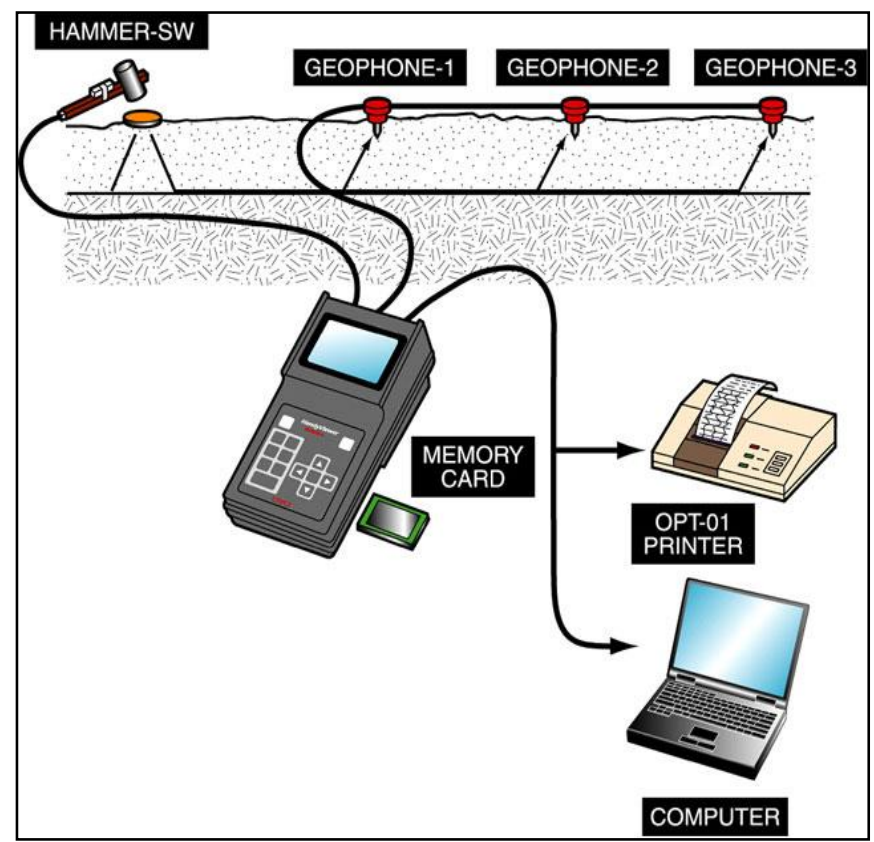

Gambar 9. Rangkaian alat seismik refraksi

(Sumber: Sipayung et al., 2018)

Pertama, konfigurasi geofon dan sumber getaran disusun hingga membentuk satu garis lurus. Kemudian kami mengatur jarak antar geofon dan sumber getaran. Setiap rekaman diakuisisi berupa data primer jarak sumber getaran dengan geofon serta waktu tiba gelombang (Sipayung et al., 2018). Berikut ini alur pengukuran seismik refraksi yang digambarkan pada gambar 10 . 


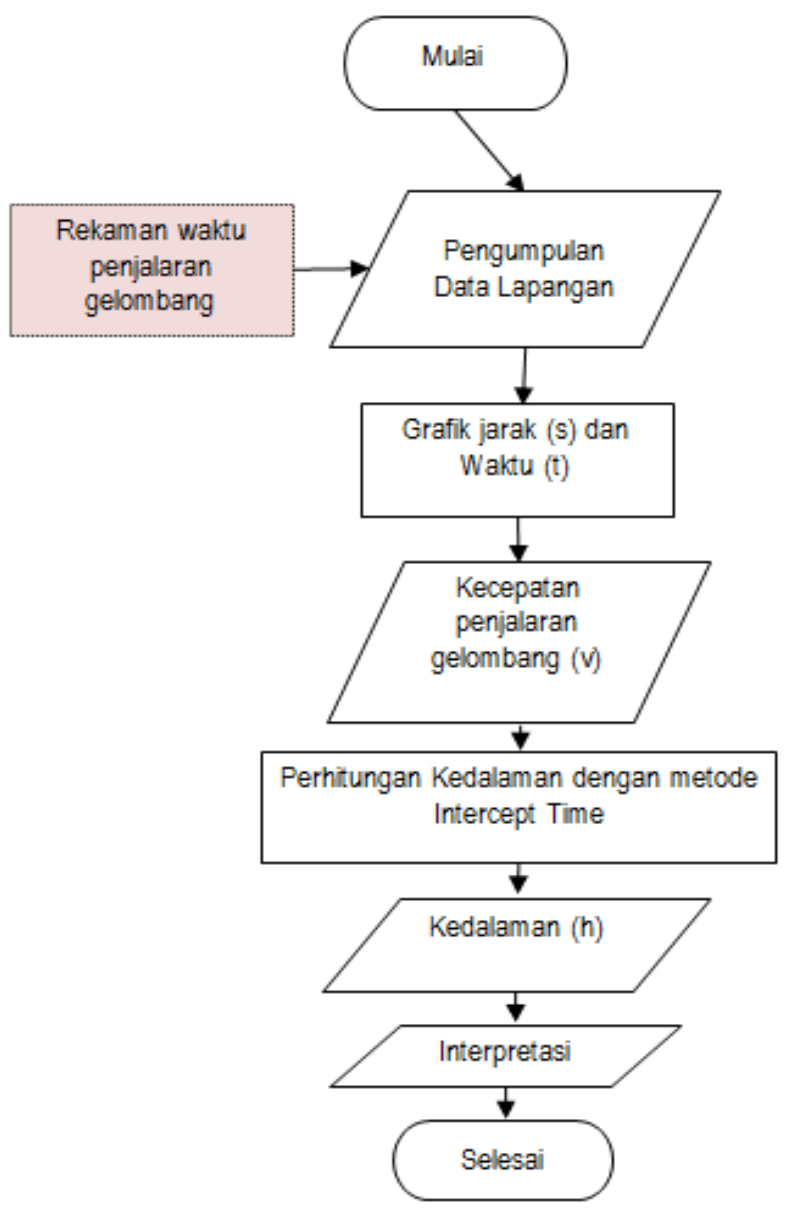

Gambar 10. Alur pengukuran seismik refraksi (Sumber: Peneliti, 2015)

Akuisi data menggunakan metode seismik refraksi ke belakang (reverse) dan metode seismik ke depan (forward). Jarak antara sumber getaran ke geofon pertama adalah 2 meter dan setiap tiga kali pukulan (stack) jaraknya ditambah kelipatan dua (Serhalawan et al., 2017). Berikut adalah ilustrasi antara geofon dan sumber getaran saat pengambilan data yang ditunjukkan pada gambar 11.

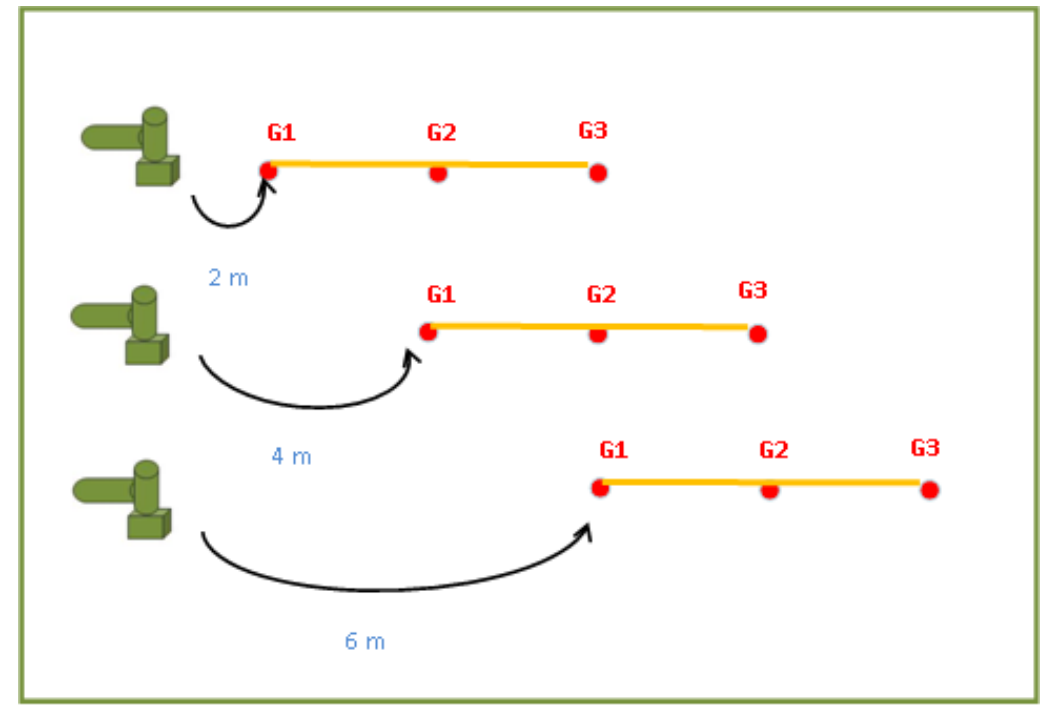

Gambar 11. Alur ilustrasi pengambilan data seismik refraksi ke depan (forward) (Sumber: Serhalawan et al., 2017)

Data primer yang diperoleh dari pengukuran kemudian diolah untuk memperoleh waktu tempuh gelombang dari sumber getaran sampai ke geofon 1, geofon 2, dan geofon 3. Waktu tempuh dari 
masing-masing geofon dirata-ratakan hingga didapatkan waktu tempuh gelombang rata-rata. Waktu tempuh tersebut kemudian dikelompokkan menurut masing-masing jarak yang sama dengan sumber getaran. Dengan menggunakan Microsoft excel, kita dapat menggambar proyeksi waktu jalar gelombang dalam sekon terhadap jarak dalam meter (Rahman et al., 2017).

Hasil dari proyeksi data tersebut didapat dari kecepatan gelombang pada lapisan tanah yang merupakan 1 (satu) / gradient (kemiringan) grafik jarak dan waktu (Setiadi et al., 2017). Setelah didapat kecepatan gelombang pada masing-masing lapisan, maka dapat diinterpretasi struktur bawah lapisan permukaan dan estimasi nilai kedalaman dari bidang batas lapisan.

\section{TEMUAN DAN PEMBAHASAN}

Studi ini merupakan upaya yang berguna untuk mitigasi bencana (Octhav et al., 2017). Penelitian mitigasi bencana alam kebumian perlu diteruskan dan dikonsep untuk berkontribusi pada keamanan nasional. Undang-Undang No. 24 Tahun 2007 tentang Penanggulangan Bencana merupakan awal baru bagi perkembangan penanganan bencana di Indonesia. Undang-Undang Penanggulangan Bencana merubah paradigma penanganan bencana di tanah air difokuskan kepada fase pra-bencana yaitu pengurangan risiko bencana seperti pencegahan, mitigasi dan kesiapsiagaan. Undang-Undang Penanggulangan Bencana menjadi landasan hukum dalam segala kegiatan penanggulangan bencana (BNPB, 2016). Selain Undang-Undang No. 24 Tahun 2007 tentang Penanggulangan Bencana beberapa regulasi lain sebagai pendukung sekaligus sebagai landasan dasar dalam penanggulangan bencana antara lain Peraturan Presiden nomor 08 tahun 2008 tentang Badan Nasional Penanggulangan Bencana, Peraturan Pemerintah nomor 23 tahun 2008 tentang Peran Serta Lembaga Internasional dan Lembaga Asing non Pemerintah dalam Penanggulangan Bencana (Rahman, 2015).

Aksi mitigasi bencana kebumian harus diawali dengan kajian risiko bencana yang bertujuan melakukan analisis tingkat ancaman, tingkat kerentanan, dan tingkat kapasitas dari setiap elemen (Aminatun \& Muntafi, 2016). Kerentanan harus dikurangi untuk menurunkan risiko terhadap potensi bencana. Pemukiman yang dibangun di luar peta rawan likuifaksi tingkat tinggi merupakan salah satu langkah mengurangi kerentanan dari segi bangunan (Aminatun, 2017). Kerentanan dari segi populasi juga harus dikurangi dengan peningkatan kapasitas. Kapasitas populasi dapat diperkuat dengan pengetahuan risiko bencana yang memadai, diiringi pelatihan kesiapsiagaan. Pelatihan kesiapsiagaan harus dilakukan tidak hanya di kalangan terbatas, tapi harus mencakup keseluruhan elemen (stakeholder) yang ada (Hadi et al., 2019). Selain daripada kapasitas populasi, juga harus diperhatikan mengenai kapasitas bangunan, dimana kapasitas bangunan memiliki peran penting dalam mengurangi risiko kerugian.

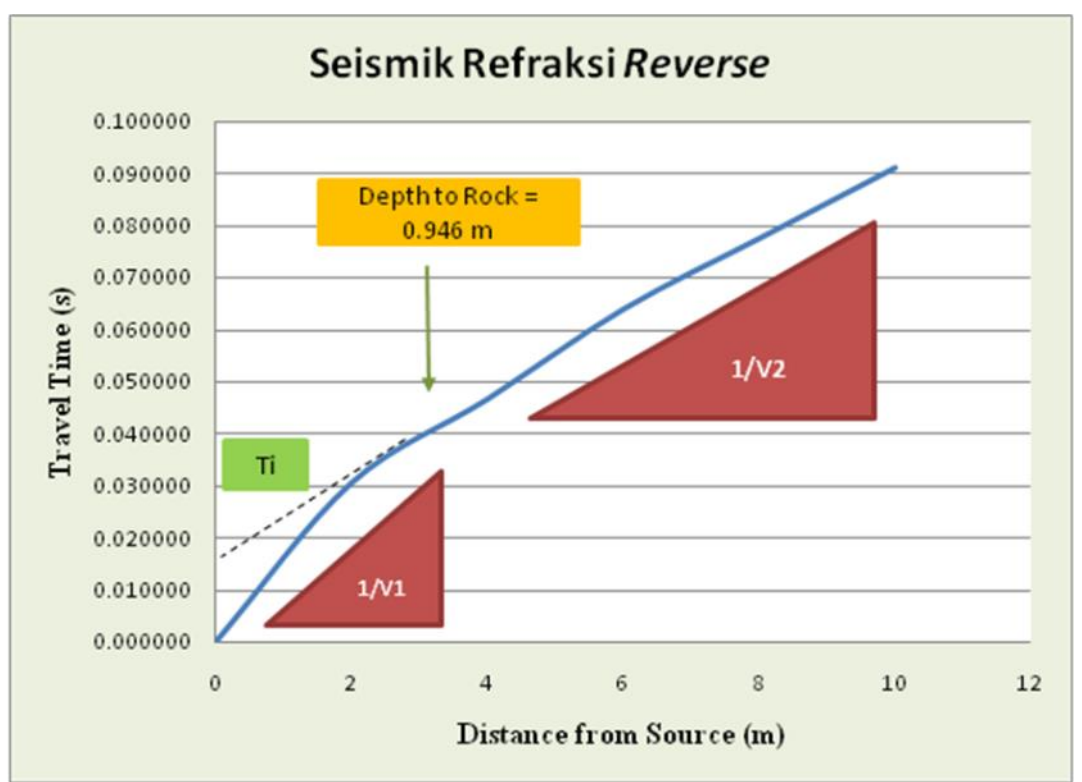

Gambar 12. Proyeksi waktu jalar gelombang seismik (sekon) terhadap jarak (meter). (Sumber: Hasil olahan data primer, 2019) 
Dari data yang diperoleh dapat diinterpretasi bahwa pada data seismik ke depan dari masingmasing kecepatan gelombang $1\left(\mathrm{~V}_{1}\right)$ dan kecepatan gelombang $2\left(\mathrm{~V}_{2}\right)$ diperoleh nilai kedalaman sedalam 3,215 meter, dan 0,946 meter, daerah lapisan ini merupakan lapisan batuan lapuk permukaan. Perbedaan hasil yang didapat antara metode seismik refraksi ke depan dengan ke belakang dipengaruhi adanya gangguan (noise) serta besar dari kekuatan sumber getaran yang diberikan (Apriani et al., 2017). Dari hasil yang diperoleh menunjukkan hubungan antara kecepatan dengan kedalaman, dimana semakin jauh lapisan bumi dari permukaan, kecepatan gelombang seismik semakin tinggi. Secara visual dapat ditampilkan pada gambar 12.

\section{SIMPULAN}

Pengukuran seismik refraksi yang dilakukan pada tanggal 10-13 Juli 2015 di area Kampus LIPI menemukan kedalaman bidang batas lapisan lapuk adalah berkisar 0.946 meter - 3.215 meter. Lalu ditemukan hubungan antara kecepatan gelombang seismik dengan kedalaman lapisan geologi. Semakin menjauh dari permukaan, kecepatan gelombang seismik semakin tinggi. Studi ini merupakan upaya yang berguna untuk mitigasi bencana kebumian dengan diawali dari pemahaman sifat tanah. Paradigma penanggulangan bencana di tanah air difokuskan kepada fase pra-bencana dalam bentuk pengurangan risiko bencana seperti pencegahan, mitigasi dan kesiapsiagaan. Ancaman dapat disebabkan oleh ketidaktahuan terhadap kondisi tanah lokal, sehingga aksi mitigasi bencana kebumian harus diawali dengan kajian risiko bencana yang bertujuan melakukan analisis tingkat ancaman, tingkat kerentanan, dan tingkat kapasitas dari setiap elemen.

\section{DAFTAR PUSTAKA}

Agus, R.N., Suardi, I., Sipayung, R. \& Sianipar, D. (2018). Local seismicity pattern around Mt. Pandan, East Java according to February 2016 earthquake swarms activity. AIP Conference Proceedings 1987, 020034.

Aminatun, S. (2017). Kajian analisis risiko bencana tanah longsor sebagai dasar dalam pembangunan pembangunan infrastruktur di Desa Sriharjo Kecamatan Imogiri Kabupaten Bantul. Jurnal Teknisia, 21(2), 372-382.

Aminatun, S., \& Muntafi, Y. (2016). Kajian analisis risiko bencana tanah longsor di Desa Terong Kecamatan Dlingo Kabupaten Bantul. Jurnal Teknisia, 21(2), 250-260.

Apriani, M., Julius, A.M., Yusuf, M., Heryanto, D.T., \& Marsono, A. (2017). Estimation of sediment thickness using power spectral analysis of gravity data, case study Capital Region of Jakarta. Jurnal Ilmiah Geomatika, 23(2), 65-74.

BNPB. (2016). Risiko Bencana Indonesia. Jakarta: Badan Nasional Penanggulangan Bencana.

Hadi, H., Agustina, S., \& Subhani, A. (2019). Penguatan kesiapsiagaan stakeholder dalam pengurangan risiko bencana alam gempabumi. Geodika: Jurnal Kajian Ilmu dan Pendidikan Geografi, 3(1), 30-40.

Nurdiyanto, B., Hartanto, E., Ngadmanto, D., Sunardi, B., \& Susilanto, P. (2011). Penentuan tingkat kekerasan batuan menggunakan metode seismik refraksi. Jurnal Meteorologi dan Geofisika, 12(3).

Octhav, A., Julius, A.M., Muzli, \& Rudyanto, A. (2017). Modified of ground motion prediction equation in Indonesia, case study: South and South-East of Sulawesi at 2011-2015. AIP Conference Proceedings. 1857, 020003.

Pusat Gempabumi dan Tsunami BMKG. (2019). Katalog gempabumi signifikan dan merusak tahun 1821-2018. Jakarta: Badan Meteorologi Klimatologi dan Geofisika.

Raharjo, S.A. (2002). Analisis kecepatan perambatan gelombang bias pada medium dan faktor kualitas medium di lereng barat Gunung Merapi. Skripsi, tidak dipublikasikan. Yogyakarta: Universitas Gadjah Mada.

Rahman, A. Z. (2015). Kajian mitigasi bencana tanah longsor di Kabupaten Banjarnegara. Gema Publica: Jurnal Manajemen dan Kebijakan Publik, 1(1), 1-14. 
Rahman, A., Marsono. A., \& Rudyanto, A. (2017). Rapid magnitude estimation using $\tau$ C method for earthquake early warning system (Case study in Sumatra). AIP Conference Proceedings. 1857, 020017.

Sagala, R.A., Harjadi, P.P.J., Heryandoko, N., \& Sianipar, D. (2017). Detailed seismotectonic analysis of Sumatra subduction zone revealed by high precision earthquake location. AIP Conference Proceedings. 1857 (1), 020015.

Serhalawan, Y.R., Sianipar, D., \& Suardi, I. (2017). The January 25th, 2014 Kebumen earthquake: A normal faulting in subduction zone of Southern Java. AIP Conference Proceedings. 1857 (1), 030002.

Setiadi, T. A. P., Rohadi, S., \& Heryandoko, N. (2017). Earthquake relocation in Mollucas Sea using teleseismic double difference method for tectonic setting analysis. AIP Conference Proceedings. 1857, 020007.

Sipayung, R., Alhafiz, M.R., Agus, R.N., \& Sianipar, D. (2018). Relocation of the February 2016 Mt. Pandan earthquake sequence using double difference with waveform cross correlation. AIP Conference Proceedings. 1987 (1), 020036.

Sismanto. (1999). Eksplorasi dengan menggunakan seismik refraksi. Yogyakarta: Gadjah Mada University Press.

Taib, M.I.T. (1985). Engineering seismology. Buku tidak dipublikasikan, Institut Teknologi Bandung Press.

Tjetjep (1995). Model simulasi struktur multi lapisan dari data seismik refraksi dengan menggunakan metode time plus minus. Skripsi, tidak dipublikasikan. Bandung: Institut Teknologi Bandung.

Tribunnews.com. (2014). 93 rumah di Banyumas rusak akibat gempa. Diakses tanggal 25 Juni 2020 dari https://jogja.tribunnews.com/2014/01/25/93-rumah-di-banyumas-rusak-akibat-gempa. 